\title{
PENGARUH PENDIDIKAN DAN LATIHAN (DIKLAT) DAN KOMPETENSI TERHADAP KINERJA KARYAWAN PADA PT. PUPUK KUJANG CIKAMPEK
}

\author{
Dedi Mulyadi \\ Universitas Buana Perjuangan Karawang \\ dedimulyadi@ubpkarawang.ac.id \\ Yana Nur Ahmad \\ Universitas Singaperbangsa Karawang \\ Yana.nurahmad76@pupuk-indonesia.com
}

\begin{abstract}
Abstrak
Penelitian ini tentang pengaruh Diklat dan kompetensi terhadap kinerja karyawan pada PT. Pupuk Kujang Cikampek. Pendidikan dan Pelatihan (Diklat) merupakan sesuatu kekuatan yang diharapkan dapat mempercepat pembinaan sumber daya manusia dengan kompetensi, kemampuan dan tingkat profesionalisme yang sesuai dengan kebutuhan dunia kerja dan pembangunan menjelang pasar bebas.

Tujuan penelitian ini adalah Mengkaji dan menganalisis 1). besaran hubungan diklat dan kompetensi karyawan; 2). Mengkaji dan menganalisis besaran pengaruh pelaksanaan diklat dan kompetensi secara parsial terhadap kinerja karyawan; 3).Mengkaji dan menganalisis besaran pengaruh pelaksanaan diklat dan kompetensi karyawan secara simultan terhadap kinerja karyawan.

Metode penelitian yang digunakan adalah metode survai dengan disain penelitian asosiatif. Sumber data diambil dari PT. Pupuk Kujang Cikampek, sebagai populasinya adalah seluruh karyawan PT. Pupuk Kujang Cikampek sebanyak 1190 orang. dengan menggunakan rumus dari Taro Yamane diperoleh sampel sebanyak 300 responden. Teknik analisis data yang digunakan yaitu Analisis Jalur dengan bantuan Mehtod Successive Interval(MSI), program komputer MicrosoftExcel 2007, dan SPSSversi 16.

Hasil penelitian menunjukan bahwa : 1) Hubungan korelasional antara diklat dengan kompetensi karyawan memiliki hubungan yang cukup kuat dan searah atau positif; 2) diklat secara parsial berpengaruh positif signifikan terhadap kinerja karyawan dan kompetensi karyawansecara parsial berpengaruh positif signifikan terhadap kinerja karyawan; 3) Diklat dan kompetensi karyawan secara simultan berpengaruh positif signifikan terhadap kinerja karyawan.
\end{abstract}

Kata Kunci : Pendidikan dan Latihan (Diklat), Kompetensi, Kinerja Karyawan

\begin{abstract}
This study about the effect of Training and competence on employee performance at PT. Pupuk Kujang Cikampek. Education and Training (Diklat) is a force that is expected to accelerate the development of human resources with the competence, ability and level of professionalism in accordance with the needs of the world of work and development ahead of the free market (AFTA).

The purpose of this study is to review and analyze 1). the magnitude of the relationship of training and employee competence; 2). Assess and analyze the magnitude of the effect of the implementation of training and competence partially on employee performance; 3). Majaji and
\end{abstract}

1.

Jurnal Manajemen \& Bisnis Kreatif 
analyze the amount of influence of the implementation of training and employee competence simultaneously on employee performance.

The research method used is survey method with associative research design. Source of data taken from PT. Pupuk Kujang Cikampek, as the population is all employees of PT. Fertilizer Kujang Cikampek as many as 1190 people. using the formula of Taro Yamane obtained sample of 300 respondents. Data analysis techniques used were Path Analysis with the help of Mehtod Successive Interval (MSI), MicrosoftExcel 2007 computer program, and SPSSversion 16.

The results showed that: 1) Correlational relationship between training and employee competence has a strong enough relationship and direction or positive; 2) training partially significant positive effect on employee performance and employee competence partially significant positive effect on employee performance; 3) Training and employee competence simultaneously have a significant positive effect on employee performance.

Keywords: Education and Training (Training), Competence, Employee Performance

\section{BAB I \\ PENDAHULUAN}

\subsection{Latar Belakang Penelitian}

Organisasi dalam mewujudkan tujuannya diperlukan sumber daya manusia (SDM) karena tumbuh kembangnya suatu organisasi tergantung dari SDM-nya. Oleh karena itu harus diperhatikan dengan baik agar terjadi peningkatan efisiensi, efektivitas, dan produktivitas kerja yang tercermin pada kinerja semua pihak khususnya para anggota penanggung jawab bidang fungsional, baik yang masuk kategori tugas pokok maupun tugas penunjang serta pimpinan penyelenggara kegiatan operasional yang dibantu karyawan teknis, operasi, dan administratif (Dwiyanto, dalam Efendi, 2004:113).

Visi misi dan tujuan perusahaan yang begitu berat memerlukan sumber daya manusia yang berkompeten. Michael Zwell (2000) mengungkapkan bahwa terdapat beberapa faktor yang dapat mempengaruhi kecakapan kompetensi seseorang yaitu sebagai berikut : keyakinan dan nilai-nilai, keterampilan, pengalaman , karaktresik pribadi, motivasi, isu emosional,kemampuan intelektual dan budaya organisasi.

Pendidikan dan Pelatihan (Diklat) merupakan sesuatu kekuatan yang diharapkan dapat mempercepat pembinaan sumber daya manusia dengan kompetensi, kemampuan dan tingkat profesionalisme yang sesuai dengan kebutuhan dunia kerja dan pembangunan menjelang pasar bebas. Pengembangan pegawai sangat diperlukan dalam sebuah instansi, karena dengan adanya program tersebut dapat membantu meningkatkan kemampuan dan keterampilan pegawai. Pengembangan pegawai juga dirancang untuk memperoleh pegawai-pegawai yang mampu berprestasi dan fleksibel untuk suatu instansi dalam geraknya ke masa depan (Soekidjo Notoatmodjo, 2003 : 103). 
Pendidikan dan pelatihan juga merupakan upaya untuk mengembangkan kemampuan intelektual dan kepribadian pegawai. Oleh karena itu setiap organisasi atau instansi yang ingin berkembang, pendidikan dan pelatihan pegawainya harus memperoleh perhatian yang lebih besar sehingga dapat meningkatkan kinerja pegawainya tersebut (Soekidjo Notoatmodjo, $2003: 30$ )

"Pengaruh Kompetensi, Pendidikan dan Pelatihan terhadap Kinerja Karyawan Pada PT Pupuk Kujang Cikampek"

\subsection{Perumusan Masalah}

Berdasarkan identifikasi masalah di atas, perumusan masalah pada penelitian ini adalah ;

1. Apakah terdapat hubungan diklat dan kompetensi karyawan pada PT Pupuk Kujang Cikampek

2. Bagaimana pengaruh diklat dan kompetensi secara parsial terhadap kinerja karyawan pada PT Pupuk Kujang Cikampek

3. Bagaimana pengaruh diklat dan kompetensi secara simultan terhadap kinerja karyawan pada PT Pupuk Kujang Cikampek

\subsection{Tujuan Penelitian}

1. Mengkaji dan menganalisis besaran hubungan diklat dan kompetensi karyawan pada PT Pupuk Kujang Cikampek

2. Mengkaji dan menganalisis besaran pengaruh pelaksanaan diklat dan kompetensi secara parsial terhadap kinerja karyawan pada PT Pupuk Kujang Cikampek

3. Mengkaji dan menganalisis besaran pengaruh pelaksanaan diklat dan kompetensi karyawan secara simultan terhadap kinerja karyawan pada PT Pupuk Kujang Cikampek

\section{BAB II \\ KAJIAN PUSTAKA}

Kinerja menurut kamus umum bahasa Indonesia adalah asal kata dasar kerja mempunyai arti "perbuatan melakukan sesuatu" (Poerwadarminta, 2002:492).

Mangkunegara (2009:9) menyatakan bahwa: "kinerja (prestasi kerja) adalah hasil kerja secara kualitas dan kuantitas yang dicapai oleh seseorang dalam melaksanakan tugasnya sesuai dengan tanggung jawab yang diberikan kepadanya".

Kinerja merupakan suatu fungsi dari motivasi dan kemampuan. Untuk menyelesaikan tugas atau pekerjaan seseorang sepatutnya memiliki derajat kesediaan dan tingkat kemampuan tertentu. Kinerja merupakan perilaku yang nyata yang ditampilkan setiap orang sebagai prestasi kerja yang dihasilkan oleh karyawan sesuai dengan perannya dalam perusahaan (Rivai, 2010).

Sumber daya manusia yang memiliki kompetensi sangat diperlukan dalam rangka penyelenggaraan organisasi yang baik (good governance dan clean government). Kompetensi 
adalah suatu kemampuan untuk melaksanakan atau melakukan suatu pekerjaan atau tugas yang dilandasi atas keterampilan dan pengetahuan serta didukung oleh sikap kerja yang dituntut oleh pekerjaan tersebut (Wibowo, 2010).

Pengertian pendidikan dan pelatihan merupakan salah satu upaya pengembangan sumber daya manusia, terutama untuk mengembangkan kemampuan intelektual dan kepribadian manusia. Penggunaan istilah pendidikan dan pelatihan dalam suatu institusi atau organisasi biasanya disebut dengan diklat, (Oemar Hamalik, 2007:10).

Dimensi pendidikan dan pelatihan dalam penelitian ini adalah: (1) Tujuan pendidikan dan pelatihan, (2) Kurikulum, (3) Metode belajar mengajar.

Tujuan pendidikan dan pelatihan adalah merupakan rumusan kemampuan atau perilaku baru yang lazimnya dirumuskan dalam katagori pengetahuan, kecerdasan, sikap, keterampilan yang diharapkan untuk dimiliki oleh sasaran pendidikan dan pelatihan setelah menyelesaikan program pendidikan dan pelatihan (Soekidjo Notoatmodjo, 2009:27).

Kurikulum berkenaan dengan segala upaya yang dilakukan oleh lembaga pendidikan dan pelatihan untuk, mempengaruhi peserta didiknya dalam proses belajar. Secara etimologi, Soekidjo Notoatmojo (2009:33) mengemukakan bahwa "Kurikulum berasal dari Bahasa Romawi, dari kata curriculum (bentuk tunggal) dan curricula (bentuk jamak) yang berarti lapangan perlombaan atau suatu jarak yang harus ditempuh seorang siswa atau mahasiswa untuk mencapai suatu tingkat tertentu".

Metode belajar mengajar adalah cara, pendekatan, alat yang digunakan pada kegiatan belajar mengajar dalam menyampaikan bahan pengajaran kepada sasaran pendidikan dan pelatihan untuk mewujudkan tujuan pendidikan dan pelatihan secara efektif dan efisien, dalam hal ini adalah hubungan antara pendidik dan peserta didik. dalam kaitannya dengan penelitian ini, yang menjadi indikator dari dimensi metode belajar mengajar adalah : 1) Metode yang digunakan;2) Cara penyajian; 3) Fasilitas diklat.

\section{Kerangka Pemikiran}

1. Pengaruh Kompetensi terhadap Kinerja Karyawan

Faidal (2010) Kompetensi juga berpengaruh secara langsung terhadap kinerja pegawai. Ilman Ataunur dan Eny Ariyanto (2015) dalam penelitiannya membuktikan bahwa kompetensi berpengaruh positif singifikan terhadap kinerj a karyawan

2. Pengaruh Diklat terhadap kinerja karyawan

Berdasarkan hasil penelitian Verra Nitta Turere (2013) menunjukkan bahwa variabel pendidikan dan pelatihan mempunyai pengaruh terhadap kinerja karyawan. Variasi (naikturunnya) kinerja karyawan yang dijelaskan oleh variabel pelatihan sebesar 67,9\% sedangkan sisanya $32,1 \%$ dijelaskan oleh faktor-faktor lain. Kesimpulannya adalah pendidikan dan pelatihan dapat mempengaruhi peningkatan kinerja karyawan, sehingga hipotesis yang diajukan adalah benar dan dapat diterima

3. Pengaruh kompetensi dan pelatihan terhadap Kinerja

4.

Jurnal Manajemen \& Bisnis Kreatif 
Ilman Ataunur dan Eny Ariyanto (2015) dalam penelitiannya menunjukan bahwa kompetensi dan diklat secara bersama-sama mempunyai pengaruh positif dan signifikan terhadap kinerja karyawan, hah ini menunjang penelitian Fikri (2010) dan Hariani (2015)

Berdasarkan kerangka pemikiran di atas dapat disusun kerangka model konseptual penelitian sebagai berikut :

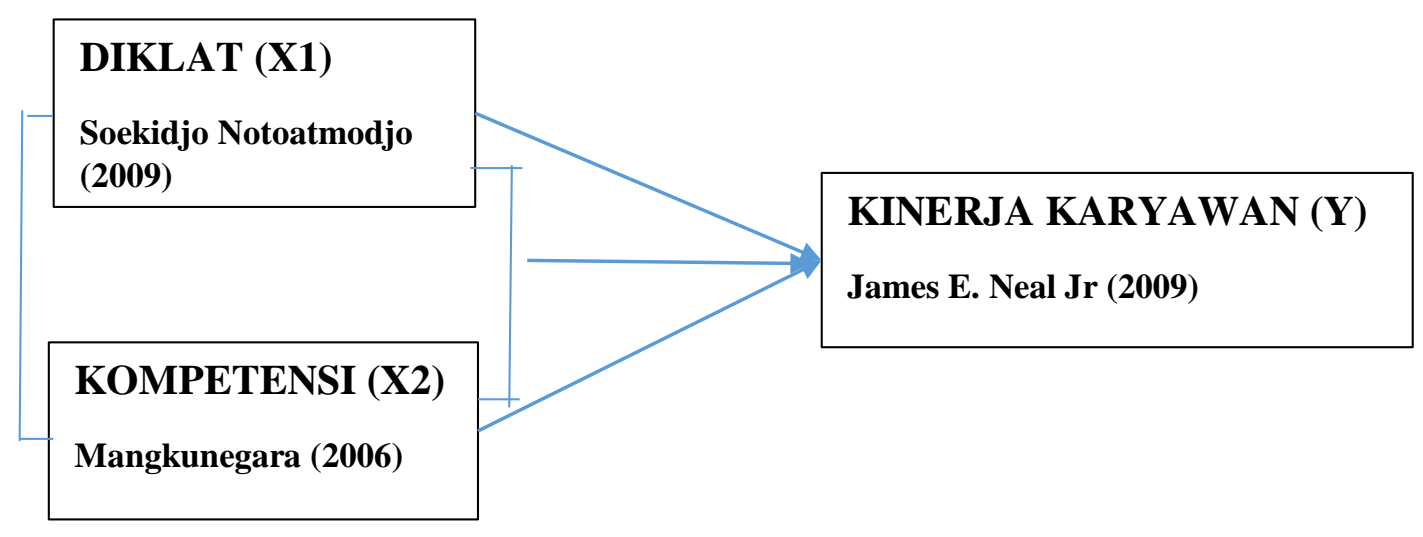

\section{Gambar 1 : model kerangka konseptual}

\section{Hipotesis}

H1: Kompetensi berpengaruh positif signifikan terhadap kinerja karyawan PT. Pupuk Kujang Cikampek

H2: Diklat berpengaruh positif signifikan terhadap kinerja karyawan PT. Pupuk Kujang Cikampek

H3: Kompetensi dan Diklat secara bersama-sama berpengaruh positif signifikan terhadap kinerja karyawan PT. Pupuk Kujang Cikampek

\section{BAB III}

\section{METODE PENELITIAN}

Penelitian ini bertujuan untuk menguji pengaruh variabel kompetensi dan pelatihan terhadap kinerja, baik secara parsial maupun simultan. Adapun metode penelitian yang digunakan adalah metode survai dengan disain penelitian asosiatif.

\subsection{Variabel Penelitian dan Operasionalisasinya}

Berdasarkan definisi konsep tentang variabel-variabel dalam penelitian ini, selanjutnya dioperasionalisasikan seperti tertera dalam tabel berikut : 
Tabel : 1

Operasionalisasi variabel

\begin{tabular}{|c|c|c|}
\hline Variabel & Dimensi & Indikator \\
\hline \multirow{3}{*}{$\begin{array}{l}\text { (Soekidjo } \\
\text { Notoatmodjo, } \\
\text { 2009:27). }\end{array}$} & 1. Tujuan Diklat & $\begin{array}{l}\text { 1. Relevansi dengan kebutuhan } \\
\text { organisasi. } \\
\text { 2. Jelas, mudah diobservasi dan realistik. }\end{array}$ \\
\hline & $\begin{array}{l}\text { 2. Metode } \\
\text { Diklat }\end{array}$ & $\begin{array}{l}\text { 1. Metode yang digunakan. } \\
\text { 2. Widyaiswara. } \\
\text { 3. Fasilitas diklat. } \\
\text { 4. Proses pembeljaran }\end{array}$ \\
\hline & 3. Kurikulum & $\begin{array}{l}\text { 1. Kualitas materi kurikulum. } \\
\text { 2. Kesesuaian materi dengan kondisi } \\
\text { organisasi masyarakat. } \\
\text { 3. Jumlah materi. }\end{array}$ \\
\hline
\end{tabular}

\begin{tabular}{|c|c|c|}
\hline \multirow{8}{*}{$\begin{array}{c}\text { Kompetensi } \\
\text { Karyawan (X2) } \\
\text { Mangkunegara } \\
(2006: 112)\end{array}$} & $\begin{array}{l}\text { 1. Kemampuan } \\
\text { teknis }\end{array}$ & $\begin{array}{l}\text { 1. Semua tugas dapat ditangani } \\
\text { 2. Semua tugas diselesaikan tepat waktu }\end{array}$ \\
\hline & $\begin{array}{l}\text { 2. Kemampuan } \\
\text { sosial }\end{array}$ & $\begin{array}{l}\text { 1. Kemampuan untuk bersosilisasi } \\
\text { dengan masyrakat } \\
\text { 2. Mampu melakukan koordinasi }\end{array}$ \\
\hline & $\begin{array}{l}\text { 3. Pengetahuan } \\
\text { akan } \\
\text { pekerjaan }\end{array}$ & $\begin{array}{l}\text { 1. Pengetahuan tentang tugas } \\
\text { Pengetahuan tentang proedur kerja }\end{array}$ \\
\hline & 4. Kreativitas & $\begin{array}{l}\text { 2. Upaya mengatasi masalah pelayanan } \\
\text { 3. Upaya mengatasi masalah kerja } \\
\text { dengan rekan kerja }\end{array}$ \\
\hline & 5. Kerjasama & $\begin{array}{l}\text { 4. Dengan Pemimpin } \\
\text { 5. Dengan rekan kerja }\end{array}$ \\
\hline & 6. Inisiatif & 6. Mencari solusi dari masalah kerja \\
\hline & 7. Kemandirian & $\begin{array}{l}\text { 7. Kemampuan mengatasi masalah } \\
\text { sendiri }\end{array}$ \\
\hline & $\begin{array}{l}\text { 8. Kualitas } \\
\text { Personal }\end{array}$ & $\begin{array}{l}\text { 8. Hubungan dengan pimpinan } \\
\text { 9. Hubungan dengan rekan kerja }\end{array}$ \\
\hline
\end{tabular}

6. 


\begin{tabular}{|c|c|c|}
\hline \multirow[t]{6}{*}{$\begin{array}{c}\text { Kinerja } \\
\text { Karyawan (Y) } \\
\text { (Rivai, 2010). }\end{array}$} & Prestasi & $\begin{array}{l}\text { - Menyelesaikan tanggung jawab dan } \\
\text { tugas } \\
\text { - memberikan kepuasan kerja kepada } \\
\text { pelanggan } \\
\text { - memberikan kepuasan kerja kepada } \\
\text { pimpinan }\end{array}$ \\
\hline & Komunikasi & $\begin{array}{l}\text { - komunikasi dengan pimpinan } \\
\text { - komunikasi dengan rekan kerja } \\
\text { - komunikasi dengan pelanggan }\end{array}$ \\
\hline & Kerjasama & $\begin{array}{l}\text { - Kerjasama dengan pimpinan } \\
\text { - Kerjasama dengan rekan kerja }\end{array}$ \\
\hline & Inisiatif & $\begin{array}{l}\text { - Upaya mengatasi masalah pelayanan } \\
\text { - Upaya mengatasi masalah dengan } \\
\text { rekan kerja } \\
\text { - Mencari solusi masalah kerja }\end{array}$ \\
\hline & $\begin{array}{l}\text { Keahlian } \\
\text { Interpersonal }\end{array}$ & $\begin{array}{l}\text { - Hubungan dengan pimpinan } \\
\text { - Hubungan dengan rekan kerja }\end{array}$ \\
\hline & Pengetahuan & $\begin{array}{l}\text { - Pengetahuan tentang tugas } \\
\text { - Pengetahuan tentang prosedur kerja }\end{array}$ \\
\hline
\end{tabular}

Sumber : diolah penulis

\subsection{Sumber dan cara penentuan data}

Sumber data yang digunakan dalam penelitian ini adalah data primer dan data sekunder. Data primer diperoleh dengan cara wawancara, kuisoner dan observasi lapangan. Sedangkan data primer diperoleh dari dokumen dan data perusahaan PT Pupuk Kujang Cikampek.

Cara penentuan data dalam penelitian ini menggunakan teknik sampling probability sampling yaitu teknik sampling yang memberikan peluang yang sama bagi setiap unsur (anggota) populasi untuk dipilih sebagai sampel. Sedangkan metode pengambilan sampel yang digunakan proportionate stratified random sampling, karena pengambilan anggota sampel dari populasi dilakukan secara acak dengan memperhatikan strata golongan yang ada dalam populasi itu.

\subsection{Populasi dan Sampel}

Populasi adalah seluruh karyawan PT. Pupuk Kujang Cikampek sebanyak 1190 orang. Penentuan besarnya jumlah sampel yang diperlukan dalam penelitian ini digunakan "Tehnik Proportionate Stratified Random Sampling yaitu pengambilan sampel dari anggota populasi yang tidak heterogen secara acak dan berstrata secara proposional" dan Cluster Sampling yaitu teknik sampling yang dilakukan dengan cara mengambil wakil dari setiap wilayah geografis yang ada (Riduwan dan Kuncoro,2011:41-43). 
Penetapan jumlah sampel dengan menggunakan rumus dari Taro Yamane yang dikutip Riduwan dan Kuncoro (2011:44), sebagai berikut :

$$
n=\frac{N}{1+N d^{2}}
$$

Keterangan :

$\mathrm{n}$ : jumlah sampel

$\mathrm{N}$ : Jumlah populasi

d : presisi yang ditetapkan, $5 \%$

Dari jumlah populasi sebanyak 1190 orang, maka dengan menggunakan rumus di atas diperoleh besarnya sampel 300 responden

\subsection{Teknik pengumpulan data}

uji validitas internal kuesioner dilakukan dengan cara uji coba (tryout) pada 30 respoden. Uji validitas konstruk kuesioner menggunakan teknik korelasi product momment, dan uji konsistensi (reliabilitas) dengan teknik cronbach's alpha.

Tabel 2.

Ketentuan Penilaian Skala Likert

\section{Kualitas Persepsi Responden}

Sangat Setuju, Selalu, Benar Sekali, Baik Sekali

Setuju, Sering, Benar, Baik

Cukup Setuju, Kadang-Kadang, Cukup Benar, Cukup Baik

Tidak Setuju, Sekali-Kali, Tidak Benar, Tidak Baik

Sangat Tidak Setuju, Tidak Pernah, Sangat Tidak Baik

\begin{tabular}{cc} 
Skor & \\
\hline $\begin{array}{c}\text { Pernyataan } \\
\text { Positif }\end{array}$ & $\begin{array}{c}\text { Pernyataan } \\
\text { Negatif }\end{array}$ \\
5 & 1 \\
4 & 2 \\
3 & 3 \\
2 & 4 \\
1 & 5 \\
\hline
\end{tabular}

\subsection{Rancangan Analisis}

Kuisioner yang digunakan untuk mengumpulkan data dari variabel-variabel yang diteliti menggunakan skala likert untuk setiap jawaban diberi skor 1 sampai 5. Dalam menjawab masalah dan mengungkap tujuan penelitian yaitu menentukan besaran pengaruh variabel terhadap variabel lainnya baik pengaruh yang bersifat langsung maupun tidak langsung dilakukan dengan analisis jalur (Path-Analysis). untuk menganalisisnya diperlukan data dengan ukuran paling tidak interval sebagai persyaratan dalam menggunakan alat analisis jalur.

Alasan pemilihan metode statistik dengan analisis jalur tersebut dilakukan dengan pertimbangan, bahwa metode ini mampu memberikan kejelasan hubungan dan besaran pengaruh antar variabel penelitian yang sangat berguna bagi upaya peneliti dalam mengupas secara lebih mendalam berbagai variabel yang diteliti. (Chun Li, 1975:2).

\subsection{Uji hipotesis}

Pengujian hipotesis dilakukan melalui uji statistik untuk mengetahui pengaruh antar jalur seperti yang tertuang dalam rancangan analisis. Pengujian atas struktur dilakukan dengan

8.

Jurnal Manajemen \& Bisnis Kreatif 
menggunakan analisis jalur (Path Analysis). Analisis ini digunakan dengan pertimbangan bahwa hubungan antar variabel dalam penelitian ini bersifat korelatif dan kasualitas.

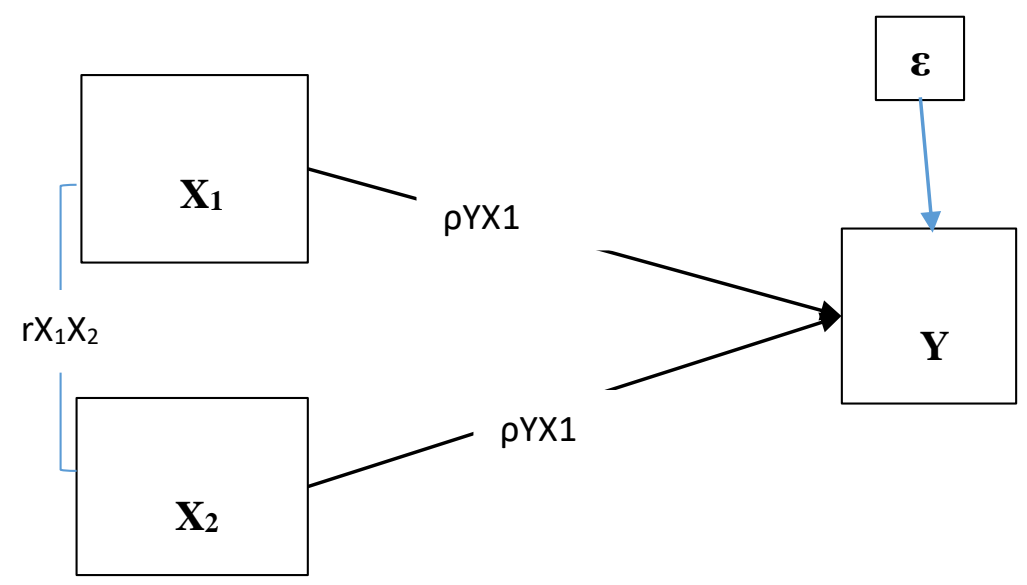

\section{Gambar 2}

Analisis jalur

\section{HASIL ANALISIS DAN UJI HIPOTESIS}

\subsection{Hasil Penelitian}

Hasil analisis korelasi product moment diperoleh besaran koefisien korelasi diantara variabel variabel pendidikan dan pelatihan dengan kompetensi karyawan didapat nilai sebesar 0,468 yang berarti mempunyai tingkat hubungan yang cukup dan searah karena nilainya positif.

Pengaruh parsial pendidikan dan latihan (diklat) $\left(\mathrm{X}_{1}\right)$ terhadap kinerja karyawan $(\mathrm{Y})$ yaitu sebesar 0,498 dan kompetensi karyawan $\left(\mathrm{X}_{2}\right)$ terhadap kinerja karyawan $(\mathrm{Y})$ yaitu sebesar 0,326. Berdasarkan pengolahan data tersebut menunjukan bahwa nilai $0,326<0,498$, maka dapat dinyatakan bahwa diklat lebih besar dan lebih dominan memberikan kontribusi terhadap kinerja karyawan dibandingkan kompetensi karyawan. Hal ini mengindikasikan bahwa para karyawan lebih dapat meningkat kinerjanya dengan penyelenggaraan pendidikan dan latihan.

Total pengaruh diklat $\left(\mathrm{X}_{1}\right)$ dan kompetensi karyawan $\left(\mathrm{X}_{2}\right)$ terhadap kinerja karyawan sebesar 0,507 atau sebesar 50,7\%. Berdasarkan hasil penelitian ini menunjukan bahwa Diklat dan kompetensi karyawan memiliki kontribusi terhadap kinerja karyawan (Y) sebesar 50.7\% sedangkan sisanya 0,493 atau sebesar $49,3 \%$ merupakan pengaruh kontribusi variabel lain $(\varepsilon)$ yang tidak diteliti.

\subsection{Uji Hipotesis}

Diklat $\left(\mathrm{X}_{1}\right)$ berpengaruh signifikan terhadap kinerja karyawan $(\mathrm{Y})$, dengan kriteria uji nilai Sig. $(0,000)<\alpha(0,05)$. Artinya Ho ditolak. Hal ini dapat dijelaskan bahwa diklat mempunyai nilai signifikansi atau bermakna terhadap pencapaian kinerja karyawan. Kompetensi karyawan $\left(\mathrm{X}_{2}\right)$ berpengaruh signifikan terhadap kinerja karyawan (Y), dengan kriteria uji nilai Sig. $(0,000)$

9.

Jurnal Manajemen \& Bisnis Kreatif 
$<\alpha(0,05)$. Artinya Ho ditolak. Hal ini menunjukan bahwa kompetensi karyawan mempunyai nilai signifikansi atau bermakna terhadap pencapaian kinerja karyawan. Diklat $\left(\mathrm{X}_{1}\right)$ dan kompetensi karyawan $\left(\mathrm{X}_{2}\right)$ berpengaruh signifikan terhadap kinerja karyawan $(\mathrm{Y})$, diperoleh nilai Sig. 0,000 $<\alpha(0,05)$. Hal ini berarti bahwa secara simultan terdapat pengaruh yang signifikan dari variabel bebas terhadap variabel tidak bebas. Artinya diklat dan kompetensi karyawan mempunyai nilai signifikansi dan bermanfaat terhadap pencapaian kinerja karyawan.

\section{KESIMPULAN DAN SARAN}

\subsection{Kesimpulan}

1. Hubungan korelasional antara diklat dengan kompetensi karyawan memiliki hubungan yang cukup kuat dan searah atau positif. Hal ini menunjukan bahwa jika diklat meningkat maka kompetensi karyawan juga akan meningkat dan sebaliknya

2. diklat secara parsial berpengaruh positif signifikan terhadap kinerja karyawan dan kompetensi karyawansecara parsial berpengaruh positif signifikan terhadap kinerja karyawan. Berdasarkan pengolahan data tersebut menunjukan bahwa diklat lebih besar dan lebih dominan memberikan kontribusi terhadap kinerja karyawan dibandingkan kompetensi karyawan.

3. Diklat dan kompetensi karyawan secara simultan berpengaruh positif signifikan terhadap kinerja karyawan.

\subsection{Simpulan}

1. Para karyawan harus dapat meningkatkan perannya sebagai motivator disamping peran-peran lain yang terdapat dalam dimensi diklat dan kompetensi.

2. Pengaruh secara parsial diklat dan kompetensi karyawan terhadap kinerja karyawan menunjukan bahwa diklat sebagai variabel dominan oleh karena itu dibutuhkan upaya peningkatan kompetensi dalam meningkatkan kinerja karyawan

3. Pengaruh simultan diklat dan kompetensi karyawan terhadap kinerja karyawan sebesar 50,7 $\%$, artinya terdapat pengaruh variabel lain yang tidak diteliti sebesar $49,3 \%$. Oleh karena itu kepada para peneliti selanjutnya untuk melakukan penelitian dengan meneliti variabel lain yang dapat mempengaruhi kinerja karyawan

10. 


\section{DAFTAR PUSTAKA}

Faidal, 2010, Pengaruh diklat, pengalaman kerja, kompetensi terhadap kinerja karyawan pada UKM di Bangkalan Madura, Universitas Trunojoyo Madura. Jurnal

Arifian, 2006. Analisis Pemahaman Budaya Perusahaan Dengan Motivasi Kerja Karyawan di PT. Pembangkit, Jawa Barat, Tesis Tidak Dipublikasikan, Magister Manajemen Agribisnis Institut Pertanian Bogor.

Dhita Ayu Meitaningrum, Imam Hardjanto, Siswidiyanto, EFEKTIVITAS PENDIDIKAN DAN PELATIHAN DALAM MENINGKATKAN KINERJA PEGAWAI (Studi pada Badan Kepegawaian Daerah Kabupaten Malang) Jurnal Administrasi Publik (JAP), Vol 1, No.3, h. 192-199. Universitas Brawijaya Malang.

Engkos Ahmad Kuncoro \& Riduwan, 2007. Cara Menggunakan dan memaknai Analisi.

Gibson et all, 1994. Organisasi Jilid 1 dan 2, ahli bahasa Agus darma, Erlangga Jakarta.

Gusmana, Agus. 2008. Pengaruh Budaya Organisasi, Disiplin Kerja dan Motivasi Kerja Terhadap Kinera Aparat Keamatan Btujajar Kabupaten Bandung Barat. Tesis Pasca Sarjana Magister Manajemen. Sekolah Tinggi Ilmu Ekonomi Pasundan.

Haris, O., Jeff, Jr. 2000. Managing People At Work, Consept and Casis in Inerpersonal Behavior. USA : John Billey And Sons Inc, New York.

Hasibuan, Malayu, SP. 2003. Organisasi dan Motivasi ; Dasar Peningkatan Produktivitas, Cetakan Keempat, Bumi Aksara, Jakarta.

Hidayat, 2007. Analisis Model Pengaruh Dimensi Kepuasan Kerja Terhadap Kinerja Karyawan Pada PT. Centralindo Medika. Universitas Wijaya Putra Surabaya.

Kuswanda, UUs. 2006. Pengaruh Kemampuan Kerja, Motivasi Kerja dan Disiplin Kerja Terhadap Kinerja Pegawai Biro Dekonsentrasi dan Tugas Perbantuan SETDA Provinsi Jawa Barat. Tesis Program Pasca Sarjana Magister Manajemen. Sekolah Tinggi Ilmu Ekonomi Pasundan.

Laporan Tahunana UPTD Puskesmas Sungaibuntu, Tim UPTD Puskesmas Sungaibuntu, 2012.

Laporan Profil Kesehatan Tahunan 2012, UPTD Puskesmas Sungaibuntu.

Luthans, F. 1995. Organization Behavior, New York USA, MC. Grow Hill Inc.

11. 
Marifah, 2005. Pengaruh Motivasi Kerja dan Budaya Organisasi Terhadap Kinerja pekerja Sosial Pada Unit Pelaksana Teknis Dinas Sosial propinsi Jawa Timur, Tesis Tidak Dipublikasikan, Magister Manajemen Agribisnis Intitut Pertanian Bogor.

Mursidi, 2009. PengaruhPendidikandanPelatihanTerhadapKinerjaKaryawan, Jurusan Manajemen Fakultas Ekonomi Universitas Muhammadiyah MalangJurnal Teknik Industri, Vol. 10, No. 2, Agustus 2009: 120-127

Moeljono Djokosantoso, 2003. Budaya Korporat dan Keunggulan Korporasi, Elex Media Komputindo, Jakarta.

Mangkunegara AP. 2001. Manajemen Sumberdaya Manusis Perusahaan (Cetakan Ke-3), Bandung PT. Remaja Rosda Karya Offset.

Mangkunegara Anwar Prabu, 2005. Perilaku dan Budaya Organisasi, Refika Aditama, Bandung.

Mirza. 2008. Hubungan Budaya Organisasi, Dukungan Organisasi dan Motivasi Kerja dengan Kinerja Karyawan PT. BRI Tbk Yogyakarta. Tesis. Progra Pasca Sarjana Program Study Psikologi. Universita Gajah Mada.

Notoatmojo Sukidjo, 2005. Metodologi Penelitian Kesehatan, Rineka Cipta, Jakarta.

Orpen. 2001. Interactive Effect Or Work Motivation And Personal Control On Employee Job Performance And Satisfation. Jurnal Off Sosila Psychology. 134, 6, p 866 - 856.

Robbins Stephen, 2002. Prinsif-prinsif Perilaku Organisasi, Terjemahana Helida, Dewi Sartika, Erlangga Jakarta.

Sedermayanti, 2000. Tatakerja dan Produktivitas Kerja, Mandor jaya, Bandung.

Setya Hendro Wardhana, 2008. Hubungan Motivasi Kerja Dan Budaya Kerja Dengan Kinerja Pegawai Sekretariat Daerah Kabupaten Siak, Tesis Tidak Dipublikasikan, Magister Manajemen Agribisnis Institut Pertanian Bogor.

Sugiyono, 2010. Metode Penelitian Kuantitatif, Kualitatif dan R\&D, Alfabeta, Bandung.

Sugiyono, 2010. Statistik untuk Penelitian, Alfabeta Bandung.

Subakti Syaiin, 2008. Pengaruh Kepuasan Kerja Terhadap Kinerja Pegawai Klinik Spesialis Bestari, Universitas Sumatera Utara, Medan. 
Teman Koesmono, H., 2005. Jurnal Manajemen dan Kewirausahaan Vol. 7 No. 2, Pengaruh Budaya Organisasi Terhadap Motivasi dan Kepuasan Kerja Serta Kinerja Karyawan Pada Sub Sektor Industri Pengolahan Kayu Skala Menengah di Jawa Timur, Fakultas Ekonomi Universitas Katholik Widya Mandala, Surabaya.

Triton Prawira Budi, 2006. SPSS 13.0 Terapan, Riset Statistik Parametrik, Penerbit CV. Andi Offset, Yogyakarta.

Verra Nitta Turere, 2013. Pengaruh pendidikand an pelatihan terhadap peningkatan kinerja karyawan pada Balai Pelatihan Teksni Pertanian Kalasey . Fakultas Ekonomi Universitas Sam Ratulangi Manado Jurnal EMBA Vol.1 No.3 Juni 2013, Hal. 10-19

Wibowo, 2007. Manajemen Kinerja, PT. Raja Grafindo Persada, Jakarta.

Whitmore, Jhon, 2002. Coaching for Performance, Seni Mengarahkan Untuk Mendongkrak Kinerja. Terjemahan Y D Helly Purnomo, Grameia, Jakarta.

Willson and Heyyel, 1987. Hand Book Of Modern Office Management and Administration Service. Mc Graw Hill Inc. New Jersey.

Wungu \& Brotoharjo, 2003. Tingkatkan Kinerja Perusahaan Anda Dengan Merit Sistem. Jakarta : Raja Grafindo Pustaka. 